\section{Wider human-rights focus for health data}

Those producing codes of conduct for life-sciences research under the European Union's General Data Protection Regulation (GDPR) should draw on established international work to secure the success of scientific data sharing and the secondary processing of personal data (see also Nature 557, 467-468; 2018).

Important guidelines include the 2017 Recommendation on Health Data Governance from the Organisation for Economic Co-operation and Development, and the Framework for

Responsible Sharing of Genomic and Health-Related Data developed by the Global Alliance for Genomics and Health (of which we are all members).

The GDPR focuses chiefly on the right to privacy. In addition, the Framework respects the right of everyone "to share in scientific advancement and its benefits" under Article 27 of the Universal Declaration of Human Rights. In our view, this wider human-rights focus will be invaluable in regulating health and genomic research, and the related proportionate interpretation and application of the GDPR.

Bartha M. Knoppers ${ }^{\star}$ Mc Gill University, Montreal, Canada. bartha.knoppers@mcgill.ca ${ }^{*}$ On behalf of 5 co-signatories (see go.nature.com/2lvg9d6 for full list).

\section{Don't let the living dead haunt citations}

The continued citation of retracted papers - or 'zombie' publications - pollutes the scientific literature with fatally flawed studies. The problem is amplified by the common practice of accessing papers through third-party websites such as Google Scholar, ResearchGate and Sci-Hub, which generally do not link to retraction notices. We propose steps publishers could take to prevent new research from citing retracted studies.

As well as displaying retraction notices more prominently on their websites, journals should post alerts across all pages of the flawed publication. Also, prefacing the paper's title with a notification would warn readers not to download the citation to reference-manager software.

Publishers can ensure that citations of zombie publications are caught before new papers go to press by running automated cross-checks of manuscript reference lists against the Retraction Watch database of retracted papers (http:// retractiondatabase.org). Universities, too, should ensure that institutional databases are updated to include retraction notices.

Sandra A. Binning University of Montreal, Canada.

Fredrik Jutfelt, Josefin Sundin Norwegian University of Science and Technology, Trondheim,

Norway.

sandra.ann.binning@umontreal.ca

\section{Reform Romania's grant-review system}

Imagine a Nobel laureate willing to review research-grant applications for Romania. She or he would first need to learn Romanian, to produce a letter of permission to participate from their university president or department chair, and to upload a declaration on Romania's platform for grant reviewers (www.brainmap.ro) confirming that they have committed no ethical misdemeanours in the course of their duties in the previous 5 years. These strictures can only lead to the further marginalization and inbreeding of a research system that is hobbled by plagiarism, paltry funds and brain drain.

According to Eurostat, Romania is in the lowest tier of European Union countries in terms of the percentage of gross domestic product (GDP) spent on research and development. In 2018 , the nation allocated only
$0.18 \%$ of GDP to its Ministry of Research and Innovation. About one-quarter of these funds are used in national calls for proposals, which are sparse, unpredictable and currently evaluated by Romanian nationals.

We urge the Romanian government to reinstate the use of international evaluators with scientific merit as the sole criterion for selection. It should also restore the requirement that proposals be written in English. Mihai Miclăuș National Re $\sim D$ Institute for Biological Sciences, Cluj-Napoca, Romania.

Octavian Micu Institute of Space Science, Măgurele, Romania. mihai.miclaus@icbcluj.ro

\section{Research hotspots in Côte d'Ivoire}

Côte d'Ivoire in West Africa has some promising research institutions, despite the considerable social and political turmoil it experienced between 1999 and 2011 (see B. Bonfoh et al. Nature 474, 569-571; 2011).

The top-ranking institutions for research productivity in 2012-16 in Côte d'Ivoire were its two largest national universities: Félix Houphouët-Boigny University and Nangui Abrogoua University, both in Abidjan (our unpublished results). In third place was the comparatively small Swiss Centre for Scientific Research in Côte d'Ivoire (CSRS), which benefits from a long-standing bilateral research partnership between Côte d'Ivoire and Switzerland. At the CSRS, mutual governance, investment and benefits are balanced with a diverse portfolio of research, education and training within four strategic axes.

In our view, a strong diversification of international funding sources, coupled with an increased share of national government funds, stand to create more centres of scientific excellence in Africa.

Bassirou Bonfoh CSRS, Abidjan, Côte d'Ivoire. Jasmina Saric, Jürg Utzinger

Swiss Tropical and Public Health Institute, Basel, Switzerland. j.saric@swisstph.ch

\title{
Pioneering women in energy physics
}

I appreciate Roger Fouquet's review of my book Energy: A Human History, but take issue with two of his criticisms (Nature 557, 162-163; 2018).

First, I did not reference solarenergy pioneer Mária Telkes because her work involved heat storage, not solar electricity the subject of my discussion.

Second, credit for the discovery of nuclear fission was, in my opinion, more complex than Fouquet implies and not attributable solely to physicist Lise Meitner.

My reading of the history is that the German radiochemists Otto Hahn and Fritz Strassmann discovered fission in Berlin in late 1938. Meitner, who was in Sweden at the time, came up with the physical explanation for this reaction with her nephew Otto Robert Frisch, after corresponding with her former colleagues Hahn and Strassmann. The journal Naturwissenschaften (renamed The Science of Nature in 2015) received the Hahn-Strassmann paper on 22 December 1938; Nature received the MeitnerFrisch paper on 16 January 1939.

It would be odd indeed had I forgotten Meitner after devoting more than 50 pages to her life and work in my 1987 history, The Making of the Atomic Bomb. Richard Rhodes Half Moon Bay, California, USA.

richardrhodes1@comcast.net

CONTRIBUTIONS

Correspondence

may be submitted to correspondence@nature. com after consulting the author guidelines and section policies at http://go.nature.com/ cmchno. 